\title{
ASSESSMENT OF DYNAMIC FEATURES OF MECHANICAL OSCILLATORS FOR A ROOT-BALLING MACHINE WITH A VIBRATING BLADE
}

\author{
Dario Friso, Marco Bietresato
}

\section{Introduction}

The first studies investigating the effects of vibration on tools were conducted in the 1950s. These studies initially focused on soil movement by bulldozers and then on soil tillage in agriculture.

[Gunn 1955] showed that the total energy, and consequently the power, required by an oscillating machine tool, which is the sum of the energy of the thrust and the energy of the oscillation, is almost equal to that of a non-oscillating tool. This result was confirmed by [Peruzzi 1988]. For some values of the ratio $\left(v_{u} / v_{a}\right)$ (tool peak velocity $v_{u}$ during the oscillation over the feed velocity $v_{q}$ ), a relative reduction can be obtained, about $10 \%$ of the required energy in the vibrating configuration.

Even if this reduction of energy is null, anyway the vibration still reduces the cutting force on the soil.

[Eggenmuller 1958] discovered that the ratio $\left(F_{o} / F_{n o}\right)$ (the cutting force of an oscillating tool over the cutting force of a non-oscillating tool), is influenced by the amplitude and frequency of the oscillation and especially by the ratio of the oscillation peak velocity to the feed velocity $\left(v_{u} / v_{a}\right)$.

In particular, he demonstrated that the force ratio decreases with increasing velocity ratio, reaching a minimum of 0.4 for $v_{u} / v_{a}$ equal to 6 . Moreover, he showed that if the amplitude of the blade motion is greater than $6 \mathrm{~mm}$ at all frequencies, the decrease in the force ratio is small. Thus, we need to obtain this amplitude of $6 \mathrm{~mm}$, without going too far, in order to minimise the cutting force.

[Brixius 1975] also reported that the traction force ratio sharply decreases for velocity ratios ranging from 1 to 1.75 , beyond which it decreases more gradually.

Paper received 06.02.2009; accepted 04.11.2009

DARIO FrISO, Associate Professor, dario.friso@unipd.it, MARCO Bietresato, Postdoctoral Fellow, Dipartimento Territorio e Sistemi Agro-forestali, Università degli Studi di Padova, Italy.
[Verma 1976] attained the same conclusion as well, observing that the force required during oscillation considerably decreases for velocity ratios ranging from 1.1 to 3 and decreases moderately for ratios ranging from 3 to 8 , while with higher kinematical ratios, the force decrease is more modest.

[Narayanarao 1982] investigated, both experimentally and theoretically, the effects of oscillation on a tool such as a chisel, by verifying that an increase in the velocity ratio $v_{v} / v_{a}$ up to 8 causes a reduction in the ratio of the forces required for the advancing $\left(F_{o} / F_{n o}\right)$ until reaching a value of 0.4 , confirming Eggenmuller's values.

More recently, [Szabo 1998] conducted experiments with an oscillating tool, pushing the velocity ratio beyond the limit of 8 , concluding that a maximum force $\left(F_{o} / F_{n o}=0.3\right)$ can be obtained by employing ratios that are equal to or greater than 17 .

There have also been works [Shkurenko 1960; Wolf 1977] in which the authors have shown that the oscillations must occur lengthwise, along the direction of motion, in order to obtain the maximum efficacy in reducing the traction force. Lateral or vertical vibrations are not very useful.

Using an inclined blade, [Smith 1972a; Smith 1972b] compared different kinds of periodic motion. With traditional harmonic motion, as was used by the previous authors, they tested square wave motion and saw tooth motion; they did not find any difference regarding the required force.

Over the past years, the field of tree nursery mechanisation has been employing this knowledge, due to the use of equipment with oscillating tools for rootballing plants. Transportation and plantation must be done with the roots contained in a hemispherical clod of original earth. This hemispherical root-ball is obtained by using a vibrating semicircular blade that cuts the soil underneath the plant (Fig. 1).

The blade oscillator is complex because the blade must oscillate and advance from the frame in order to cut the root-ball. For this reason, we have investigated, through experimental and theoretical analysis, correlations between the oscillation and cutting movements and the dynamic features of the oscillator; these 
correlations are useful for the creation of the design directive proposed in this paper.

\section{Material and methods}

\subsection{The oscillating system}

A blade is connected to an oscillator (Fig. 2) that is made up of a train of five toothed wheels (the central one is the motive, while the two extremities transmit the motion to two eccentric masses $\left.{ }^{1}\right)$. When these eccentric masses are placed opposite each other (Fig. 2), the respective centrifugal forces are balanced, but when they are rotated by $\pm \frac{\pi}{2}$ from the initial position, they cause the gear housing to alternately rotate. This causes a forced oscillation of the gear housing that is transmitted from the right side, by the shaft, to the vertical butterfly bush that is connected to the semicircular blade.

This unit, made up of the gear housing and butterfly blade, which is forced to oscillate, is then elastically connected, by four springs, as shown in Figure 2, to a constraint: the horizontal butterfly bush. This bush is not fixed, but can rotate because it is coupled to a toothed wheel that is coupled to an endless screw, which is fed by a hydraulic motor, driven by an operator in order to push the blade in the ground.

The system is oscillating in a rotating way, and it is dynamically characterised by one degree of freedom.

\subsection{The blade oscillating in air}

The equation of motion during the forced oscillation of the system with the blade in the air is:

$$
J \frac{d^{2} \alpha}{d t^{2}}+c_{a} \frac{d \alpha}{d t}+k \alpha=M_{\operatorname{men}} \operatorname{sen}(\omega t)
$$

where $J$ is the moment of inertia of the gear housing and bush blade system $\left(\mathrm{kgm}^{2}\right) ; \alpha$ is the angular position (rad), with zero as the static equilibrium of the system; $c_{a}$ is the viscous damping coefficient in air $(\mathrm{Nm} \cdot \mathrm{s}) ; k$ is the rotation elastic constant $(\mathrm{Nm} / \mathrm{rad})$, which is correlated to the linear constant $k_{1}(\mathrm{~N} / \mathrm{m})$ of the helicoidal springs (Fig. 2) by $k=z \cdot k_{l} \cdot b_{m}^{2} ; z$ is the number of springs (four in this case); $b_{m}$ is the lever arm of the springs $(\mathrm{m}) ; M_{m e}$ is the torque produced by the eccentric masses $(\mathrm{Nm})$ and is $M_{m e}=n \cdot m \cdot \omega^{2} \cdot y_{G} \cdot b_{G}$; $\omega$ is the pulsation of the torque of the eccentric masses ( $\mathrm{rad} / \mathrm{s}) ; n$ is the number of eccentric masses (two in this case); $m$ is the mass $(\mathrm{kg}) ; y_{G}$ is the mass eccentricity $(\mathrm{m}) ; b_{G}$ is the lever arm of the mass, which is the distance between the rotation axis and the blade oscillation axis (m); and $t$ is the time (s).

\footnotetext{
1 The total number of masses can be more than two, but it must be even (four, six, etc).
}

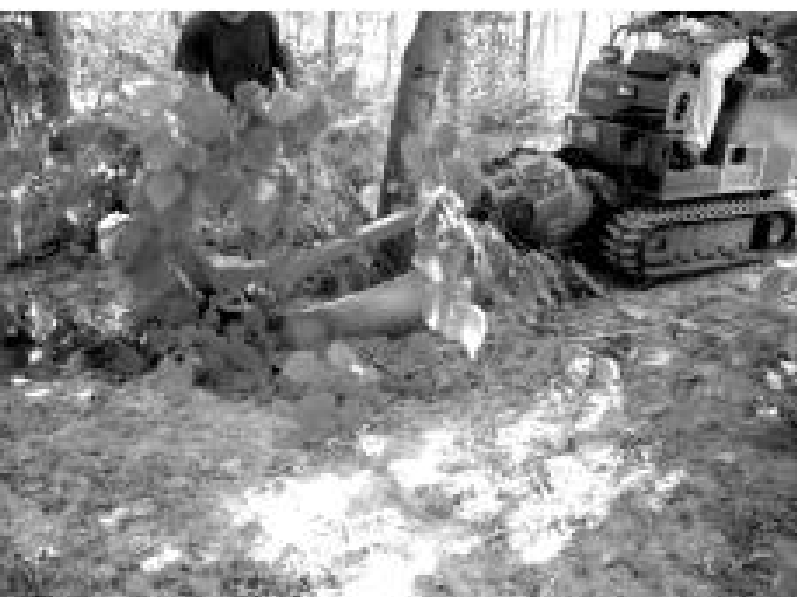

Fig. 1 - A Holmac root-balling machine: in the foreground is a semicircular blade.

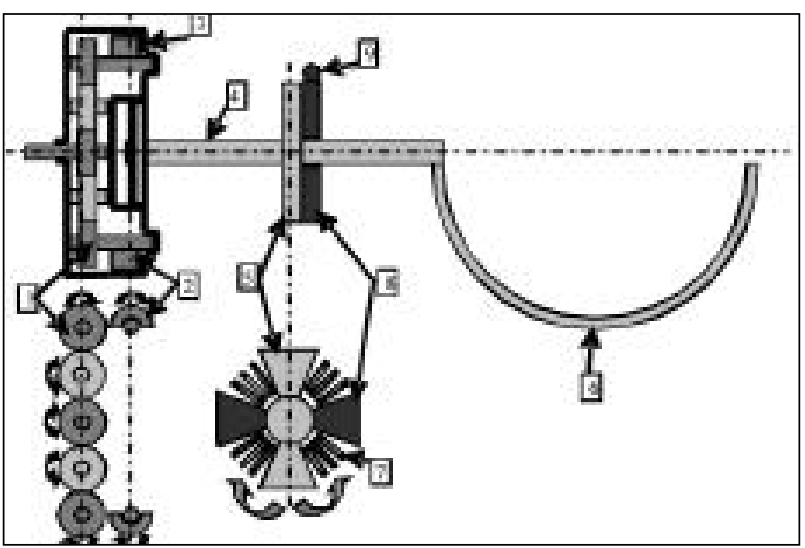

Fig. 2 - Diagram of the oscillator-blade unit: 1) gear; 2) eccentric masses; 3) housing; 4) shaft; 5) vertical butterfly bush; 6) semicircular blade; 7) springs; 8) horizontal butterfly bush; 9) toothed wheel-endless screw coupling.

Equation (1) is a not homogeneous linear differential equation with constant coefficients; the solution is the sum of a special integral of this equation and the general integral of the associated homogeneous differential equation.

This general integral is made up of exponential and/or trigonometric functions, because only these functions remain unvaried (exponential) or change their signs (trigonometric) with differentiation.

Therefore, the result is:

$$
\alpha=e^{-\frac{c^{2}}{2 / 2}}\left(C_{1} \operatorname{sen}(q t)+C_{2} \cos (q t)\right)
$$

where $C_{1}$ and $C_{2}$ are integration constants that must be determined by the initial conditions; and $q=\sqrt{\frac{k}{J}-\left(\frac{c_{v}}{2 J}\right)^{2}}$ is the natural pulsation of the damped system $(\mathrm{rad} / \mathrm{s})$.

The term in the brackets in equation (2) indicates, by the trigonometric functions, an oscillating motion of natural pulsation $q$, while the exponential term indicates damping.

Using the following values for the oscillator: $k \approx$ 
$20000 \mathrm{Nm} / \mathrm{rad}, c_{a} \approx 3 \mathrm{Nm} \cdot \mathrm{s}, J \approx 1 \mathrm{kgm}{ }^{2}$, from equation (2), we find that, after $2 \mathrm{~s}$, the natural oscillation has decreased by a factor of 20 .

Therefore, integral (2) is referred to as a very brief non-steady-state condition that can be neglected, and the solution of equation (1) is simply reduced to the special integral:

$\alpha=\frac{M_{s w}}{\left(k-J \omega^{2}\right)^{2}+c_{s}^{2} \omega^{2}}\left[\left(k-J \omega^{2}\right) \operatorname{sen}(\omega f)+c_{s} \omega \cos (\omega f)\right]$

If to the typical values of the constants $k, c_{a}$ and $J$, we add the value of the pulsation of the moment $M_{m e}$, $\omega \approx 400 \mathrm{rad} / \mathrm{s}$ because the eccentric masses rotate at about $4000 \mathrm{rpm}$, then one can note that the quantity $\left(c_{a} \omega\right)$ is about one hundred times smaller than $\left(k-J \omega^{2}\right)$. Therefore, with the blade in the air, equation (3) becomes:

$$
\alpha=\frac{M_{\alpha}}{k-J \omega^{2}} \operatorname{sen}(\omega t)
$$

The system oscillates with the same frequency $f=\frac{\omega}{2 \pi}$

$(\mathrm{Hz})$ as the forcing torque $M_{m e}$, and the resultant vibration is in phase with the forcing torque.

\subsection{The blade oscillating in the soil}

As in equation (1), we obtain the motion equation from the equilibrium between the moment of inertia $J \frac{d^{2} \alpha}{d t^{2}}$, the torque of the elastic forces $k \alpha$, the torque of the eccentric masses $M_{m e} \operatorname{sen}(\omega t)$, the torque of soil cutting $M_{t}$ (caused by the thrust of the hydraulic engine on the blade by the endless screw, the toothed wheel, the horizontal butterfly bush and the springs (Fig. 2) and the friction torque of the blade in the soil $M_{R}$.

From Coulomb's law, $M_{R}$ is constant as regards the velocity $\frac{d a}{d t}$, but changes its sign with the velocity (Fig. 3). Therefore, $M_{R}$ is a square wave periodic function, and it is dephased by the angle $\psi$ from the sinusoidal function of the forcing torque $M_{m e}$ because the velocity $\frac{d \alpha}{d t}$ is dephased by the same angle $\psi$.

This phase displacement was previously unknown; therefore, we could not approximate the square wave by a Fourier series development. Thus, we introduced a first approximation, considering the friction torque as a sinusoidal function such as $M_{i}^{\prime}(\omega t-\psi)=c_{i} \frac{d \alpha}{d t}$. From this equation, we can obtain the damping coefficient in the soil $c_{t}$ by substituting in the function $M^{\prime}(\omega t-\psi)$ the peak value, that is, the amplitude of the rotating vector, which is found by considering that the function $M_{R}^{\prime}(\omega t-\psi)$ has a surface subtended in the range $\left(-\psi, \frac{\pi}{2}-\psi\right)$ that is equal to the surface subtend- ed by the original square wave $M_{R}(\omega t-\psi)($ Fig. 4). In other words, we obtained an energetic equivalence due to the surfaces subtended by the two functions, corresponding to the work lost to friction.

Using the integrals of the two functions, we obtain for the amplitudes:

$$
M_{x}^{\prime}-\frac{\pi}{2} M_{R} \text {. }
$$

Using Coulomb's law, the amplitude of the friction torque $M_{R}$ is:

$M_{z}=$ Friction force $-L$ ever $-2 \mu G \cdot \frac{D}{\pi}$, where $D$ is the root-ball diameter $(\mathrm{m})$ that, divided by $\pi$, represents the lever arm of the friction force arising from the friction interactions of the semicircular blade; $\mu$ is the external friction coefficient; and $G$ is the weight on the blade $(\mathrm{N})$, which passes from a null value, when the blade meets the soil at the beginning and at the end of the cutting movement, to a maximum value when the blade stands vertically at the maximum depth.The factor of 2 appears because there is a weight $G$ on the upper side of the blade, along with an equal and opposite reaction to $G$ that acts on the lower side of the blade. We know by experience that the total weight of the extirpated whole is half made up of the root-ball and half of the epigea part of the plant. At the maximum depth of the blade, we consider that $G$

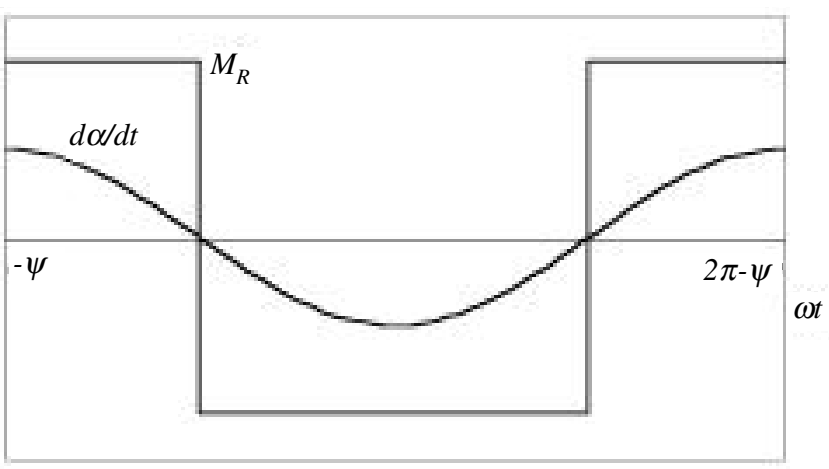

Fig. 3 - Friction torque $M_{R}$ in phase with the velocity d_/dt.

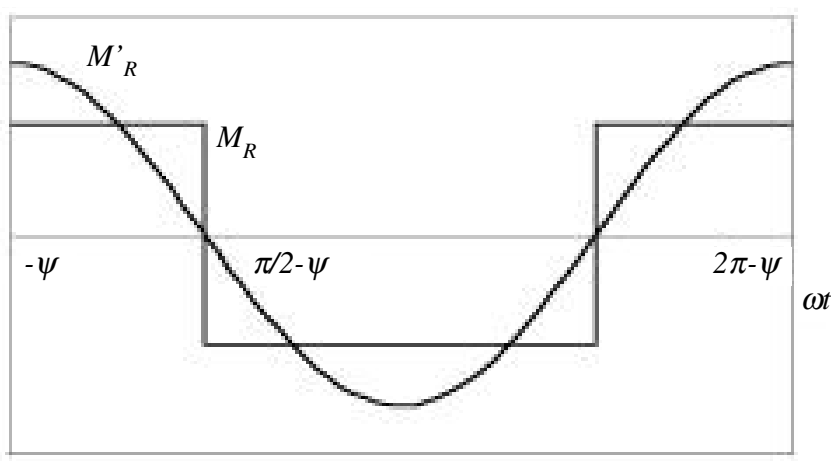

Fig. 4 - The square wave of $M_{R}$ approximated to the harmonic wave $\mathrm{M}_{\mathrm{R}}^{\prime}$. 
on the blade corresponds only to the part of the clod that is on the blade. This is a plausible hypothesis because the part of the root-ball that we still have to cut does not put weight on the blade, and the cut portion weigh on the hole. As we know the contribution of the epigea part of the plant, it is easy to describe the weight $G$ as twice that of the soil that is directly on the blade:

$G=2 \rho \frac{\pi}{8} D^{2} B \cdot g ; \rho$ is the volumetric mass of the soil $\left(\mathrm{kg} / \mathrm{m}^{3}\right) ; B$ is the blade width $(\mathrm{m})$; and $g$ is the acceleration due to gravity $\left(\mathrm{m} / \mathrm{s}^{2}\right)$. Using this, we have:

$$
M_{n}^{\prime} \approx \mu \cdot \rho \frac{\pi}{4} D^{3} B \cdot g
$$

This is an approximate formula that, with typical values of $B$ and $D$, introduces an error of only $2 \%$.

Returning to the determination of the damping coefficient in soil $c_{t}$, we need to substitute $\frac{d a}{d t}$ with the corresponding peak value, which is the velocity amplitude.

Here, we introduce another approximation by considering that this peak value is that obtained for the vibration in the air, which is determined by taking the derivative of equation (4):

$\frac{d \alpha_{0}}{d t}=\alpha_{0} \cdot \omega=\frac{M_{a t} \omega}{k-J \omega^{2}}$. Finally, to a first approximation, the damping coefficient in soil is:

$$
c_{r}=\frac{\mu \rho \pi D^{3} B g\left(k-J \omega^{2}\right)}{4 M_{m} \omega}
$$

Now, we can write the differential equation of motion for the system with the blade in the soil:

$$
J \frac{d^{2} \alpha}{d t^{2}}+c_{f} \frac{d a}{d t}+k a=-M_{f}+M_{\operatorname{sw}} \operatorname{sen}(\omega t)
$$

The special integral is:

$$
\alpha=-\frac{M_{i}}{k}+\frac{M_{\omega s}}{\sqrt{\left(k-J \omega^{2}\right)^{2}+c_{r}^{2} \omega^{2}}} \operatorname{sen}(\omega t-\phi)
$$

where the first term represents the constant angular deformation of the springs caused by the cutting torque $M_{t}$, while the second term is the angle of harmonic oscillation with a phase lag $\varphi$ from the sinusoidal wave of the forcing torque $M_{m e}$. This angle ranges between $\frac{\pi}{2}$ and $\pi$ because we have, based on typical values for the quantities of $\omega, k$ and $J$ indicated previously, $\omega>\sqrt{\frac{\hbar}{J}}$ and we have:

$$
\operatorname{tg}(\phi)=\frac{c_{i} \omega}{k-J \omega^{2}}
$$

The value of the peak of the oscillation (amplitude) is now $\alpha_{0}=\frac{M_{2}}{\sqrt{\left(k-J \omega^{2}\right)^{2}+c_{i}^{2} \omega \nu^{2}}}$. Using this, we can correct equation (6), by again calculating the damping coefficient $c^{\prime}$ :

$$
c_{r}^{+}=\frac{\mu \rho \pi D^{3} B g \sqrt{\left(k-J \omega^{2}\right)^{2}+c_{r}^{2} \omega^{2}}}{4 M_{m e} \omega}
$$

In this way, we eliminate the second approximation of the mathematical model because we can use in equation (8) the value of $c^{\prime}$, calculated using equation (10).

\subsection{The cutting torque of the soil}

The cutting torque $M_{t}$ was found experimentally by measuring the cutting time $t_{t}$ and the pressure $p$ of the oil that enters the hydraulic engine, which mechanically feeds the toothed wheel-endless screw coupling.

This engine has a constant cubic capacity, which is determined by the hydraulic pump. The flow rate $Q$ of the hydraulic oil is constant because the hydraulic pump operates at a constant speed. As with the experimental data from the constructor, we know the flowrate $Q$ and the efficiency $\eta_{m}$ of the pump. After experimentally determining the maximum pressure $p$, which occurs when the blade is vertical at its maximum depth, we found the usable power $P_{u}$ for soil cutting: $P_{u}=Q \cdot p \cdot \eta_{m}$.

The feed velocity of the blade, in its semicircular motion, is constant for the above-mentioned reasons (volumetric hydraulic pump and engine with constant cubic capacity and constant speed).

In the case that the blade meets an obstacle such as a large stone or root, the cutting torque increases to such a value that the pressure of the oil reaches the calibration value of the safety valve $(17 \mathrm{MPa})$. The cutting torque $M_{t}$ then stabilises itself at a maximum value, and the blade, by its vibration, slowly breaks the rock or cuts the root and then continues its run at the constant speed determined by the gear ratio of the toothed wheel-endless screw coupling and the hydraulic engine speed.

The experiments were conducted on soil without asperities such as stones or roots; for this reason, a measurement of the total cutting time allows us to combine the constant cutting speed and the usable power, that is, $P_{u}=M_{t} \cdot \pi / t_{t}$, where $\pi(\mathrm{rad})$ is the total angle that must be covered by the blade in time $t_{t}(\mathrm{~s})$.

By comparing the two expressions of power, we can obtain $M_{t}$ :

$$
M_{t}=\frac{Q \cdot P^{\prime} \eta_{n} \cdot l_{t}}{\pi}
$$

The reliefs were made using a Holmac root-balling machine (Fig. 1) that has an oscillator with the features given in Table 1 with a blade $0.9 \mathrm{~m}$ in diameter. The cut, repeated five times, was made on typical treenursery soil, that is, a medium textured soil with $19.1 \%$ moisture, an external friction coefficient $\mu$ with the steel blade of 0.53 and a volumetric mass of 1.57 .

At the end, we performed cutting tests, similar to the tests done with the 0.9-m-diameter blade, but with blades $1.1 \mathrm{~m}$ and $1.2 \mathrm{~m}$ in diameter in order to deter- 
mine the influence of the diameter $D$ of the root-ball on the cutting torque $M_{t}$.

\section{Results and discussion}

The geometric and dynamic features of the oscillator and of the 0.9-m-diameter blade are listed in Table 1.

\begin{tabular}{|c|c|c|}
\hline Linear elastic constant & $k_{l}(\mathrm{~N} / \mathrm{m})$ & 572000 \\
\hline Number of springs & $Z$ & 4 \\
\hline $\begin{array}{c}\text { Lever arm of the } \\
\text { springs }\end{array}$ & $b_{m}(\mathrm{~m})$ & 0.087 \\
\hline $\begin{array}{c}\text { Rotational elastic } \\
\text { constant }\end{array}$ & $k(\mathrm{Nm} / \mathrm{rad})$ & 17318 \\
\hline $\begin{array}{c}\text { Moment of inertia of } \\
\text { oscillator+blade }\end{array}$ & $J\left(\mathrm{kgm}^{2}\right)$ & 1.4 \\
\hline Number of masses & $N$ & 4 \\
\hline Mass & $m(\mathrm{~kg})$ & 1.27 \\
\hline Eccentricity & $y_{G}(\mathrm{~m})$ & 0.0212 \\
\hline Mass lever arm & $b_{G}(\mathrm{~m})$ & 0.163 \\
\hline $\begin{array}{c}\text { Torque of the eccentric } \\
\text { masses }\end{array}$ & $M_{m e}(\mathrm{Nm})$ & 2775 \\
\hline $\begin{array}{c}\text { Pulsation of torque of } \\
\text { the eccentric masses }\end{array}$ & $\omega(\mathrm{rad} / \mathrm{s})$ & 398 \\
\hline Root-ball diameter & $D(\mathrm{~m})$ & 0.9 \\
\hline Blade width & $B(\mathrm{~m})$ & 0.25 \\
\hline
\end{tabular}

TABLE 1 - Geometric and dynamic features of the oscillator.

In contrast, Table 2 shows the results of the cutting tests with the 0.9-m-diameter blade. The table includes the flow rate $Q$ and the hydraulic oil maximum pressure $p$, the hydraulic engine efficiency $\eta_{m}$, the cutting time of the root-ball $t_{t}$ and, thanks to the calculation by equation (11), the cutting torque $M_{t}$.

In Table 2 , the values of the external friction coefficient $\mu$ are listed as well as the rough damping coefficient $c_{t}$ and the exact one $c^{\prime}$, obtained by equations (6) and (10), using the geometric and dynamic features given in Table 1.

For the case of the blade oscillating in the air, as in paragraph 2.2, we neglect the relative damping and use the values of the geometric and dynamic quantities of the oscillator listed in Table 1. As a result, equation (4) gives the course of the harmonic angular oscillation $\alpha$ of the $0.9-\mathrm{m}$-diameter blade, which is displayed in Figure 5.

On the other hand, the angular oscillation $\alpha$ of the 0.9-m-diameter blade in the soil is represented in Figure 6. This is obtained by using integral (8) with both the rough damping coefficient $c_{t}$ obtained from equation (6) and the exact one $c^{\prime}$, obtained from equation (10). The two oscillations appear to overlap because the differences in the amplitude $\alpha_{0}$ and the phase displacement $\varphi$ are negligible (1.3 and $1.1 \%$, respectively).

A comparison between Figures 5 and 6 allows us to show the phase lag $\varphi$, calculated using equation (9). The phase lag, with a value of about 2.7 rad, confirms the discussion presented in paragraph 2.3 .

\begin{tabular}{|c|c|c|}
\hline Hydraulic oil flow rate & $Q\left(\mathrm{dm}^{3} / \mathrm{s}\right)$ & 0.252 \\
\hline Hydraulic oil max. pressure & $p(\mathrm{MPa})$ & 5.50 \\
\hline Standard deviation & $\sigma_{p}(\mathrm{MPa})$ & 0.45 \\
\hline Hydraulic engine efficiency & $\eta_{m}$ & 0.7 \\
\hline Cutting time & $t_{t}(\mathrm{~s})$ & 11.2 \\
\hline Standard deviation & $\sigma_{t}(\mathrm{~s})$ & 0.5 \\
\hline Cutting torque & $M_{t}(\mathrm{Nm})$ & 3460 \\
\hline External friction coefficient & $\mu$ & 0.53 \\
\hline Rough damping coefficient & $c_{t}(\mathrm{Nm} \cdot \mathrm{s})$ & 216.8 \\
\hline Exact damping coefficient & $c^{\prime}{ }_{t}(\mathrm{Nm} \cdot \mathrm{s})$ & 235.3 \\
\hline
\end{tabular}

TABLE 2 - Results of the cutting tests with the root-balling machine with the 0.9-m-diameter blade.

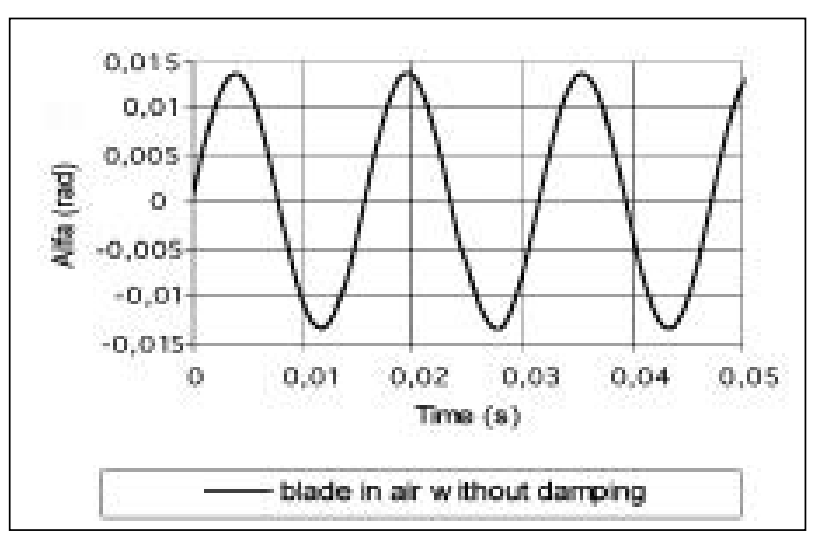

Fig. 5 - Angular oscillation $\alpha$ for vibration in air calculated neglecting the damping.

Table 3 joins together, referring to the 0.9-m-diameter blade, the oscillation amplitudes $\alpha_{0}$ in the air without damping and in the soil with two damping coefficients, with the relative phase displacement $\varphi$.

We also present the errors in the comparison between the rough and the exact damping, with negligible values, and we show the amplitude error, which is quite small at only $9.1 \%$, between the condition in the air without damping and in the soil.

Hence, the oscillation amplitude in the soil can be easily estimated by equation (4) in relation to the condition in the air, resulting in an acceptable error. In this way, we avoid calculating the soil damping coefficient and hence avoid using equation (8).

If we wanted to determine the phase displacement $\varphi$ by using equation (9), we would need to determine the above-mentioned soil damping coefficient in the rough form through the use of equation (6) because we know by equation (10) that the difference between this and the exact one is negligible.

The phase displacement $\varphi$ can be useful in determining the power required by the oscillator $P_{o}$.

We obtained this value by using the expression $P_{o}=\left(M_{m e}\right)_{\text {eff }}\left(d \alpha_{0} / d t\right)_{\text {eff }} \cdot \cos \psi$, where the effective values of the quantities, equivalent to the amplitudes multiplied by $\sqrt{2} / 2$, are used; $d \alpha_{0} / d t=\alpha_{0} \omega$; and the phase displacement $\psi$ is the phase lag between the forcing torque $M_{m e}$ and the velocity $d \alpha / d t$.

We find that $\psi=\varphi-\pi / 2$ because this velocity is ahead by $\pi / 2$ in comparison to the oscillation $\alpha$, and 


\begin{tabular}{|c|c|c|}
\hline Angular amplitude in air & $\alpha_{0}(\mathrm{rad})$ & 0.01358 \\
\hline Phase displacement in air & $\varphi(\mathrm{rad})$ & 0 \\
\hline $\begin{array}{c}\text { Rough angular amplitude } \\
\text { in soil }\end{array}$ & $\alpha_{0}(\mathrm{rad})$ & 0.01251 \\
\hline $\begin{array}{c}\text { Rough phase displacement } \\
\text { in soil }\end{array}$ & $\varphi(\mathrm{rad})$ & 2.742 \\
\hline $\begin{array}{c}\text { Exact angular amplitude in } \\
\text { soil }\end{array}$ & $\alpha_{0}(\mathrm{rad})$ & 0.01235 \\
\hline $\begin{array}{c}\text { Exact phase displacement } \\
\text { in soil }\end{array}$ & $\varphi(\mathrm{rad})$ & 2.712 \\
\hline $\begin{array}{c}\text { Error of amplitude in soil } \\
\text { rough-exact }\end{array}$ & $(\%)$ & 1.3 \\
\hline $\begin{array}{c}\text { Error of phase } \\
\text { displacement in soil rough- } \\
\text { exact }\end{array}$ & $(\%)$ & 1.1 \\
\hline $\begin{array}{c}\text { Error of amplitude } \\
\text { in air-in soil } \\
\text { rough-exact }\end{array}$ & $(\%)$ & 9.1 \\
\hline $\begin{array}{c}\text { Linear oscillation } \\
\text { amplitude of blade }\end{array}$ & $\begin{array}{c}A_{0}=\alpha_{0} D \cdot 10^{3} / 2 \\
(\mathrm{~mm})\end{array}$ & 5.6 \\
\hline Velocity ratio & $v_{u} / v_{a}=\alpha_{0} \omega t_{t} / \pi$ & 17.5 \\
\hline $\begin{array}{c}\text { Maximum compression of } \\
\text { the springs }\end{array}$ & $\begin{array}{c}\left(M_{t} / k+\alpha_{0}\right) b_{m} 10^{3} \\
(\mathrm{~mm})\end{array}$ & 18.5 \\
\hline
\end{tabular}

TABLE 3 - Amplitudes, phase displacements and errors calculated for the 0.9-m-diameter blade: in the air and in the soil.

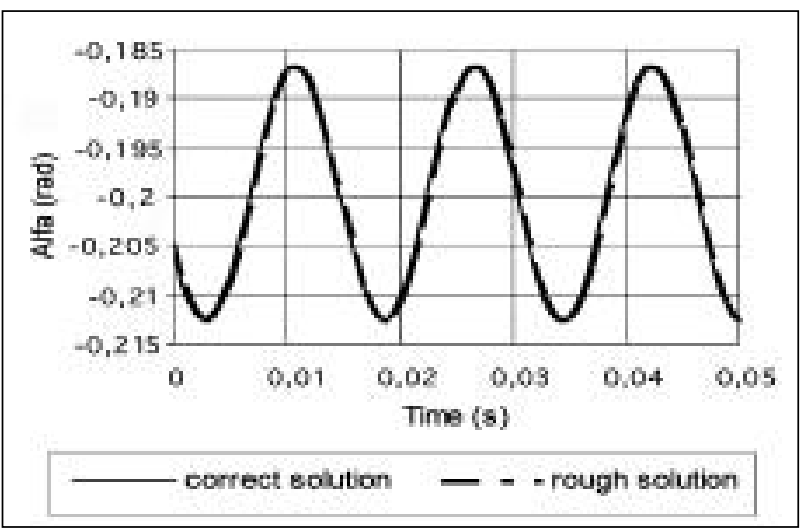

Fig. 6 - Angular oscillation $\alpha$ for vibration in the soil for the 0.9$\mathrm{m}$-diameter blade. The exact and the approximate solutions overlap.

the oscillation lags behind by $\varphi$ in comparison to $M_{m e}$.

Table 3 also reports the linear amplitude of the oscillation of the blade, $A_{0}=\alpha_{0} D / 2(\mathrm{~mm})$, which we must compare to the value of $6 \mathrm{~mm}$ indicated by [Eggenmüller 1958] as the amplitude that must be reached in order to obtain an optimised reduction of the cutting torque $M_{t}$. We must also consider the velocity ratio of the peak velocity of oscillation over the feed velocity of the blade, which is calculated by $v_{u} / v_{a}$ $=\alpha_{0} \omega \cdot t / \pi$.

The maximum compression of the springs, $\left(M / k+\alpha_{0}\right) b_{m}$, appears at the end of table 3 , but it is very important and must be compared to the total space $S_{t}$ available between the coils.

If the coils come into contact, this will transmit the vibration to the drive of the blade rotation as well as to the whole chassis of the root-balling machine. This situation must be avoided for ergonomic and machine durability reasons.

Now, we present a design directive as a final summary of the obtained results and of the data found in the literature, such as: the minimum value of the oscillation amplitude of the blade $(6 \mathrm{~mm})$ for an optimal reductive effect of the cutting torque and the indication that this reductive effect is proportional to the velocity ratio $\left(v_{v} / v_{a}\right)$, which should be equal or greater than 17.

Therefore, we must attempt to achieve a maximum value of the pulsation of the torque of the eccentric masses $\omega$, which requires the highest possible rotation speed that is compatible with the centrifugal forces and the structural strength of the rotating members.

Moreover, the total space $S_{t}$ between the coils must be larger than the maximum compression of the springs, that is, $S_{t} \geq\left(M / k+\alpha_{0}\right) b_{m}$.

Let us consider the following: that $k=z \cdot k_{l} \cdot b_{m}^{2}$ (as derived in paragraph 2.2); that $\alpha_{0}$ can be determined from equation (4), by $\alpha_{0}=\frac{M_{\sim}}{k-J \omega^{2}}$; that the oscillation amplitude of the blade $A_{0}=\alpha_{0} D / 2$ must be at least equal to $6 \cdot 10^{-3} \mathrm{~m}$; and that the linear elastic constant $k_{l}$ and the total space $S_{t}$ between commercial spring coils are predetermined data. By this, we can calculate the lever arm of the springs $b_{m}$ :

$$
b_{s}=\frac{D \cdot S_{i}}{4 A_{0}}-\sqrt{\frac{D^{2} S_{f}^{2}}{16 A_{0}^{2}}-\frac{M_{i} D}{2 A_{0} z \cdot k_{j}}}
$$

Moreover, we can choose the pulsation value $\omega$ in relation to the structural strength of the rotating and oscillating members, and we can calculate the moment of inertia $J$ of the entire oscillating structure; therefore, we can determine the torque of the eccentric masses $M_{m e}$, and we can determine how to obtain it by the appropriately choosing the number of masses $n$, their mass $m$, the eccentricity $y_{G}$ and the lever arm of the masses $b_{G}$ :

$$
M_{\omega}=n \cdot m \cdot \omega^{2} y_{G} \cdot b_{\sigma} \geq \frac{2 A_{0}\left|z \cdot k_{i} b_{\omega}^{2}-J \omega^{2}\right|}{D}
$$

Finally, if we set the velocity ratio $v_{u} / v_{a}$ to be equal to at least 17 , by knowing the velocity $v_{u}=\alpha_{0} \omega D / 2$, we will be able to find the feed velocity of the blade $v_{a}$ and therefore the hydraulic engine speed and the gear ratio of the toothed wheel-endless screw coupling.

In order to calculate the lever arm of the springs $b_{m}$ using equation (12), we must find the cutting torque $M_{t}(\mathrm{Nm})$, which depends on the properties of the soil and the root-ball diameter and hence the blade diameter $D(\mathrm{~m})$. The soil properties were determined at the end of paragraph 2.4 , and now, we investigate the influence of the diameter $\mathrm{D}$. The results are presented in Figure 7, which shows a parabolic outline of the torque well represented by the following equation $\left(\mathrm{R}^{2}=0.98\right)$ :

$$
M_{,}=5190 D^{3}-1575 D^{2}+1058 D
$$




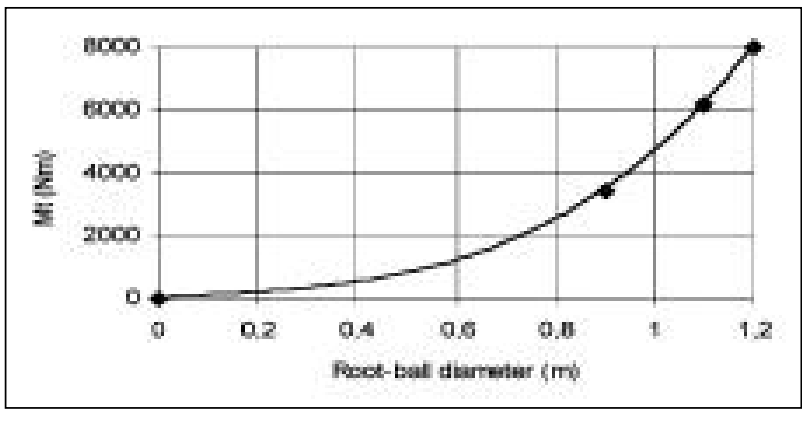

Fig. 7 - Cutting torque $M_{t}$ vs. root-ball diameter $D$.

\section{Conclusions}

Based on a theoretical analysis, we have found that the oscillating motion of the mechanical oscillator for a root-balling machine cutting blade in the soil is a harmonic motion that is greatly dephased with regard to the forcing torque of the eccentric masses and that the amplitude of this motion in the soil can be predicted by a simple equation of motion in the air with an acceptable error.

From the experimental assessment of the cutting torque of a blade on typical tree-nursery soil, we are able to calculate the deformation of the springs. If we add this to the amplitude of the oscillation, we can predict whether the coils of the springs will come into contact with each other. This must be absolutely avoided because otherwise, the vibrations will be transmitted to the whole root-balling machine.

We have combined these results together with those reported in the literature with reference to minimising the cutting torque resulting from vibration. We have presented them in a possible design directive for mechanical oscillators, in order to provide the optimal characteristics of the springs, eccentric masses and their speeds, beginning with the soil conditions, the diameter of the root-ball and the inertia of the oscillating system.

\section{References}

Brixius W.W., Weber J.A., Soil failure characteristics for oscillating tillage and bulldozer blader models, Transactions of ASAE, 1975, 18, 633-637.
Eggenmüller A., Oscillating implements: kinematics and experiments with model, Grundlagen der Landtechnik, 1958, 10, 55-69.

Gunn J., Tramontini V.N., Oscillation of tillage implements, Journal of Agricultural Engineering Research, 1955, 36, 725-729.

Narayanarao P.V., Verma S.R., Effect of the mode of action of an oscillating soil-working tool on draft and power requirements. A theoretical analysis and an experimental verification, Soil and Tillage Research, 1982, 2, 177197.

Peruzzi A., Brunello Consorti S., Di Ciolo S., Discissura del terreno con attrezzi vibranti portati e trainati, Rivista di Ingegneria Agraria, 1988, 3, 149-156.

Shkurenko N.S., Experimental data on the effect of oscillatiion on the cutting resistence of soil, Journal of Agricultural Engineering Research, 1960, 5, 226-232.

Smith J.L., Dais J.L., Flikke A.M., Theoretical analysis of vibratory tillage, Transactions of ASAE, 1972a, 15, 831833.

Smith J.L., Hallmann K., Flikke A.M., Experimental analysis of vibratory tillage, Transactions of ASAE, 1972b, 15, 834-837.

Szabo B., Barnes F., Stures S., Ko H.Y., Effectiveness of vibrating bulldozer and plow blades on draft forces reduction, Transactions of ASAE, 1998, 41(2), 283-290.

Verma S.R., Some investigations on oscillating inclined blade for potato harvesting, Ph. D. Thesis, Indian Inst. Technol., Kharagpur, India, 1976.

Wolf D., Shmuelevich I., Vibrating subsoilers in clod forming soils, ASAE Paper N. 77-1010, 1977, 1-10.

\section{SUMMARY}

A theoretical analysis of the oscillating motion produced by a mechanical oscillator for the vibrating blade of a root-balling machine was carried out. The result was harmonic motion with a strong phase displacement with respect to the forcing torque of the eccentric masses; however, the amplitude can be approximately calculated by in-air motion analysis.

Experiments were also carried out in order to determine the cutting torque of the blade in typical treenursery soil.

These results, together with the indications of other literature reports, were used to propose a possible design directive.

Keywords: mechanical oscillator, vibrating blade, root-balling machine, cutting soil. 
01_Friso(549)_01 26-01-2010 9:40 Pagina 8 